Article

\title{
Promoting the Use of Reusable Coffee Cups through Environmental Messaging, the Provision of Alternatives and Financial Incentives
}

\author{
Wouter Poortinga ${ }^{1,2, *(\mathbb{D})}$ and Louise Whitaker ${ }^{3}$ \\ 1 Welsh School of Architecture, Cardiff University, Bute Building, King Edward VII Avenue, \\ Cardiff CF10 3NB, UK \\ 2 School of Psychology, Cardiff University, Tower Building, 70 Park Place, Cardiff CF10 3AT, UK \\ 3 Bewley's Tea and Coffee UK Ltd., 8 Century Point, Cressex Business Park, Halifax Road, \\ High Wycombe HP12 3SL, UK; Louise.Whitaker@Bewleys.co.uk \\ * Correspondence: PoortingaW@cardiff.ac.uk; Tel: +44-0-2920-874-755
}

Received: 14 February 2018; Accepted: 16 March 2018; Published: 19 March 2018

\begin{abstract}
It is estimated that 2.5-10 bn disposable coffee cups are used every year in the U.K. Most of these cups end up in landfill or as litter, as the majority of poly-coated paper cups are not recyclable or not recycled. Here, we report on a field experiment that was conducted at twelve university and business sites to examine whether the use of reusable cups can be promoted through easily implementable measures. The study found that both environmental messaging and the provision of alternatives increased the use of reusable cups. While a charge on disposable cups increased their use as well, a discount on reusable cups did not. The effects for the individual measures were modest, but additive, meaning that the greatest behavioural change was achieved with a combination of measures. None of the measures negatively impacted the total number of hot drink sales. One university continued with the charge after the experiment had finished and distributed more reusable cups for free among their students. This boosted the use of reusable cups up to $33.7 \%$ across three cafés. This shows that a charge in combination with the provision of alternatives can increase the use of reusable cups substantially in the long term.
\end{abstract}

Keywords: coffee cups; field experiment; latte levy; environmental messaging; provision of alternatives; financial incentives; charge; discount; sustainable behaviour

\section{Introduction}

\subsection{Background}

It is estimated that between 2.5 and 10 bn disposable coffee cups are used every year in the U.K. alone $[1,2]$. This is expected to increase further due to continuing growth in the coffee shop sector. The number of coffee shops has quadrupled since 2000, and the forecast is that there will be 30,000 of them by 2025 [3]. Almost half of all hot drinks in coffee shops are sold in disposable cups, which is partly due to the on-the-go nature of much of the coffee and tea consumption in the U.K. [2].

It is estimated that fewer than one out of 400 cups is being recycled [3]. Many of the poly-coated paper cups therefore end up in landfill or as litter. In addition, disposable coffee cups generate about one-and-a-half-times their weight in carbon dioxide emission [4,5]. It is difficult to recycle disposable coffee cups for a number of technical, economic and social reasons. Most importantly, the majority of disposable cups are made of a paper body with an attached internal lining made out of polyethylene [6]. While it is technically possible to separate the plastic from the paper, this can only be done in specialist facilities, of which there are only three in the UK [3]. The materials from disposable coffee cups are of high volume. but low value, making it uneconomical to transport them over great distances for 
recycling [4]. In addition, there are currently few opportunities for consumers to recycle disposable cups that are taken away from coffee shops. Even when disposable cups are used in or returned to a coffee shop, they may not be recyclable because of contamination with organic materials or other food packaging [7]. While biodegradable cups appear an obvious solution, very few would make it to compost as a result of consumer confusion about which cups can and cannot be composted and a lack of access to organic bins. The use of biodegradable cups could also lead to more littering, as they may be seen as less harmful to the natural environment. Drink containers, including disposable coffee cups, are already among the most discarded items in English cities [8] and may end up as litter in the marine environment [9]. It is estimated that currently, more than half a million cups are littered every day in the UK [1].

\subsection{Strategies for Behaviour Change}

In order to reduce litter and the volume and weight of coffee cup waste being sent to landfill, it is important to consider the waste hierarchy model. That is, reducing the creation of waste materials may be a more effective and economical way of preventing waste than the recovery of these materials, in particular when they are high volume low value [10]. This then requires a change of consumer behaviour when buying coffee or tea on the go.

There are several ways to change behaviour [11-13]. Vlek listed a number of informational and structural strategies, including education/provision of information, appeals to values and morality and social modelling and support, as well as the provision of alternatives, regulation and financial instruments, respectively [11]. Information campaigns to change behaviour have been around since the earliest days of the environmental movement, but have been met with varied success [14]. Providing information may result in more knowledge, but that does not necessarily translate into behaviour change [15]. Environmental messages may be more effective when they appeal to normative values and morality or contain practical information about how to change behaviour, rather than just containing factual information [15-19]. Indeed, social norms are among the most important predictors of pro-environmental behaviour [20]. Social modelling, based on social learning theory [21], holds that people may learn from observing others performing a behaviour; although this may also happen when others set a bad example [22]. Awareness raising in combination with the provision of alternatives is one of the most effective ways of changing behaviour [12]. Introducing legislation to discourage certain behaviours is another strategy, but needs to be enforced. Governments have become increasingly reluctant to use this option because of the costs involved and fear of a public backlash [23]. Financial incentives, such as discounts and charges, are part of the standard suite of instruments available to policy makers to encourage and discourage behaviour, respectively. Recent research on single-use carrier bag usage has shown that charges, as a behaviour change instrument, can be highly effective [24]; although there is a risk that they work as an external incentive and therefore weaken someone's internal motivation to do good for the environment [25]. The English plastic bag charge appears however to have acted as a catalyst to raise further waste awareness among the general public [26] and started a public debate on whether charges could be applied to other single-use items such as disposable coffee cups [27].

\subsection{The Field Study}

The different strategies discussed here may be more or less effective, depending on the specific context in which behaviour change is sought. There is therefore a need to design and test interventions to show how effective they may be in reducing environmental impacts in those different contexts [12]. In this paper, we report on a field study that was set up to explore how the use of reusable coffee cups can be encouraged through easily implementable measures that any café could take. In particular, it examined whether: (1) environmental messaging, the provision of (reusable) alternatives and financial incentives are effective ways of promoting the use of reusable cups in the short term; (2) they have an impact on the total number of hot drink sales; and (3) a combination of measures, including a 
charge on disposable cups, can promote the use of reusable cups in the long term. The first two aims of the study were tested in a field study co-designed by the two authors of this paper. The third aim of the study was explored through a case study of a single university site that continued with the intervention and recorded sales for an extended period.

\section{Methods}

\subsection{Procedure and Data Preparation}

The field study took place between September and December 2016 and involved twelve university and business café sites. The sites were standard work-place cafés that were predominantly visited by university staff/students and office workers, respectively. The eight university sites were at major café locations of four UK higher education institutions (see the Acknowledgements). The four business sites were located in the southeast of England and run by a single contract caterer (see the Acknowledgements). The in-house café sites cater for specific office-based businesses and organisations. Each site implemented a different set of measures, combining environmental messages, the provision of reusable alternatives and financial incentives to promote the use of reusable coffee cups. It was attempted to balance the different measures across the university and business sites, although that was not always possible (see Table 1). All twelve sites displayed multiple showcards and/or posters with environmental messages about the number of cups ending up in landfill and asking customers to bring their own cup. Figure 1 shows the messages that were used on the showcards and posters. The showcards and posters were designed by the sponsor and provided free of charge to the different sites. At one site, additional messages were distributed via intranet and social media. Eight of the twelve sites started to sell reusable cups as part of the intervention. The cups were sourced by the sites themselves or supplied at cost price by the sponsor. At four of the twelve sites, reusable cups were distributed free of charge to customers at the start of the intervention. The cups were made available by the sponsor for the purpose of the study. Four of the twelve sites introduced a financial incentive to encourage the use of reusable cups. Three of them provided a discount for customers when they used a reusable cup. The size of the discount was determined by the café managers themselves, but they were asked to keep them between 15 and 25 pence. One site introduced a 25 pence charge on disposable cups after reducing the price of the coffee by the same amount. That means that a coffee in a disposable cup would take the price back to where it was before. The pricing structure of the charge was therefore the same as for a discount, but customers had to pay extra for using a disposable cup rather than receiving a discount for not using one. Where prices had changed because of a charge or discount, new menu boards were provided by the sponsor for the purpose of the study.

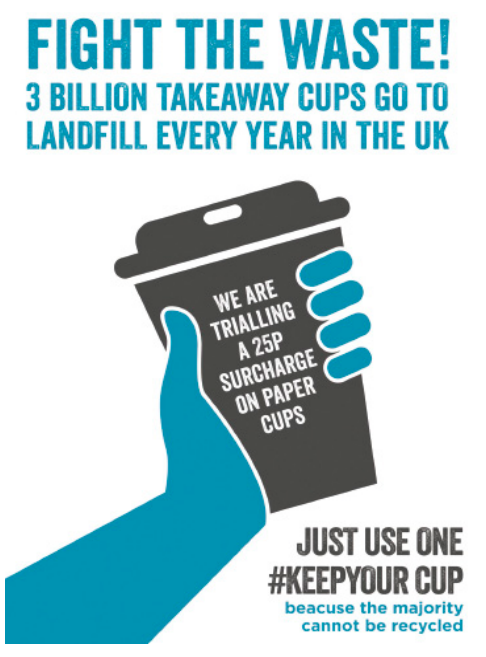

KEYS. WALLET. PHONE. KEEP CUP.

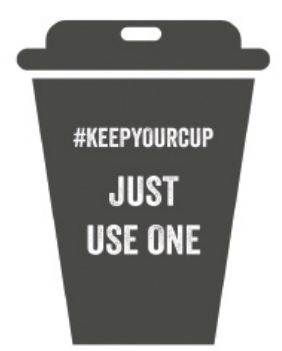

REMEMBER YOUR CUP WHEN YOU'RE WALKING OUT THE DOOR \& KEEP PAPER CUPS OUT OF UK LANDFILLS

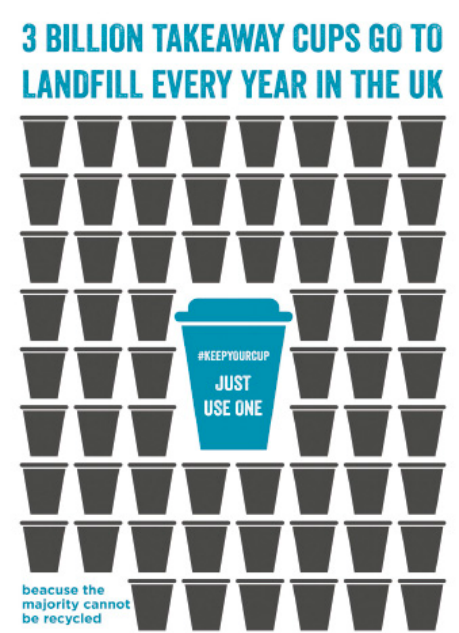

Figure 1. Examples of posters and showcards used in the study. 
Table 1. The proportion of hot drink sales with reusable cups at the twelve university and business sites in the before and after periods.

\begin{tabular}{|c|c|c|c|c|c|c|c|c|}
\hline \multicolumn{2}{|c|}{ Study Site } & \multirow{2}{*}{$\begin{array}{l}\text { Messaging } \\
\text { Posters/ } \\
\text { Showcards }\end{array}$} & \multicolumn{2}{|c|}{ Provision of Alternatives } & \multicolumn{2}{|c|}{ Financial Incentive } & \multicolumn{2}{|c|}{$\begin{array}{l}\text { Proportion of Hot Drink } \\
\text { Sales with Reusable Cups }\end{array}$} \\
\hline Number & $\begin{array}{c}\text { University } \\
\text { or Business }\end{array}$ & & $\begin{array}{c}\text { Reusable } \\
\text { Cups for Sale }\end{array}$ & $\begin{array}{c}\text { Free Reusable } \\
\text { Cups Distributed }\end{array}$ & Charge & Discount & $\begin{array}{l}\text { Before, in \% } \\
\quad \text { M (SD) }\end{array}$ & $\begin{array}{l}\text { After, in \% } \\
\text { M (SD) }\end{array}$ \\
\hline 1 & University & $\mathrm{Y}$ & $\mathrm{Y}$ & $\mathrm{Y}$ & $\mathrm{Y}$ & $\mathrm{N}$ & $5.1(1.7)$ & 17.4 (5.5) \\
\hline 2 & Business & Y & Y & $\mathrm{Y}$ & $\mathrm{N}$ & Y & $1.8(0.5)$ & $12.4(3.4)$ \\
\hline 3 & Business & $\mathrm{Y}$ & $\mathrm{Y}$ & $\mathrm{N}$ & $\mathrm{N}$ & $\mathrm{Y}$ & $4.9(0.8)$ & $6.0(0.6)$ \\
\hline 4 & University & $\mathrm{Y}$ & $\mathrm{Y}$ & $\mathrm{N}$ & $\mathrm{N}$ & $\mathrm{N}$ & $0.0(0.0)$ & $9.0(3.0)$ \\
\hline 5 & University & $\mathrm{Y}$ & $Y$ & $\mathrm{~N}$ & $\mathrm{~N}$ & $\mathrm{~N}$ & $0.4(0.3)$ & $1.1(0.6)$ \\
\hline 6 & University & $\mathrm{Y}$ & Y & $\mathrm{N}$ & $\mathrm{N}$ & $\mathrm{N}$ & $1.4(0.4)$ & $1.3(0.5)$ \\
\hline 7 & University & $\mathrm{Y}$ & $\mathbf{Y}$ & $\mathrm{N}$ & $\mathrm{N}$ & $\mathrm{N}$ & $0.7(1.3)$ & $0.3(0.5)$ \\
\hline 8 & Business & $\mathrm{Y}$ & $Y$ & $\mathrm{~N}$ & $\mathrm{~N}$ & $\mathrm{~N}$ & $7.5(2.7)$ & $24.0(4.6)$ \\
\hline 9 & University & $\mathrm{Y}$ & $\mathrm{N}$ & $\mathrm{N}$ & $\mathrm{N}$ & Y & $13.7(6.4)$ & 17.5 (3.3) \\
\hline 10 & University & $\mathrm{Y}$ & $\mathrm{N}$ & $\mathrm{Y}$ & $\mathrm{N}$ & $\mathrm{N}$ & $0.3(0.7)$ & $4.4(9.1)$ \\
\hline 11 & University & $\mathrm{Y}$ & $\mathrm{N}$ & $\mathrm{Y}$ & $\mathrm{N}$ & $\mathrm{N}$ & $0.9(1.7)$ & $7.1(6.1)$ \\
\hline 12 & Business & Y & $\mathrm{N}$ & $\mathrm{N}$ & $\mathrm{N}$ & $\mathrm{N}$ & $4.4(1.6)$ & $5.7(2.4)$ \\
\hline Overall & & & & & & & $3.3(4.4)$ & $7.6(8.1)$ \\
\hline
\end{tabular}

Café managers were asked to capture their hot drink sales for five consecutive weeks before and for five consecutive weeks after the intervention (five weeks typically equated to 25 days of sales). Data were recorded on a daily basis in a standardised format and included the total number of coffees and other hot drinks sold, the number of drinks sold in reusable cups and the number of drinks sold in single-use disposable cups. A dataset was created that included two outcome (dependent) variables, i.e.,: (1) the daily total number of hot drink sales; and (2) the daily proportion of hot drink sales with reusable cups. There were twelve sites and the total number of sale days ranged from $40-55$ per site $(M=50)$. This produced a dataset of 600 data points for the dependent variables. The predictor (independent) variables were the intervention measures of environmental messaging, reusable cups being for sale, distribution of free reusable cups among customers, a charge on disposable cups and a discount for using a reusable cup. These measures were included as dummy variables $(0=$ not present; $1=$ present) for the days during the before and after periods. Table 1 list the intervention measures taken at the twelve sites.

The University of Winchester continued with the intervention after the formal study had ended (Study Site 1; see Table 1) and rolled out the charge across three café sites on their premises. They kept recording their hot drink sales in the same standardised way until September 2017, and during that period they took a number of additional measures to promote the use of reusable cups. We report the findings as a case study of the long-term effects of a coffee cup charge in conjunction with other measures. The results are subdivided into three periods, i.e., from 6 November 2016-26 February 2017 (Period 1), after the official part of the study had finished, but before an additional 2500 free reusable cups were distributed among students; from 27 February 2017-21 May 2017 (Period 2), from when the free reusable cups were distributed until the end of the 2016-2017 academic session; and from 22 May 2017-17 September 2017 (Period 3), after the students had left for the 2016-2017 academic session.

\subsection{Statistical Analysis}

The data were analysed from an interrupted time series (ITS) perspective. ITS involves the analysis of repeated measurements, in this case daily hot drink sales, that can be used to evaluate interventions [28]. It allows the effects of the intervention to be separated from other extraneous trends within the data. ITS is particularly useful for evaluating the effectiveness of population-level (or in this case: café-level) interventions that have been implemented at a clearly-defined point in time. This approach can help to see whether there is a step-change in an outcome series linked to an 'interruption' that happened at a specific point in time, as well as changes in temporal trends. The analysis involved the use of the time series of the daily hot drink sales in the before and after 
periods of the intervention (with the 'interruption' being the implementation of the different measures). A multilevel version of ITS regression analysis was conducted, with the daily sales nested within the twelve intervention sites. Analyses were conducted with MLWin 2.36 [29]. Parameters were estimated using Markov chain Monte Carlo (MCMC) methods with 50,000 iterations. Only the fixed effects are reported.

The basic statistical model involved two 'time' variables, indicating the time elapsed since the start of the study and the time elapsed since the start of the intervention respectively; a dummy variable indicating the period of the study (i.e., before or after the implementation of the measures); and dummy variables indicating whether the sites sold reusable coffee cups within the café, distributed free reusable coffee cups or introduced a discount or a charge. The parameters associated with the time variables indicate underlying temporal tends in the data and whether the trend changed in the intervention period, respectively. As all sites displayed environmental messages as part of the intervention, the before-after dummy variable gives an indication of the effects of environmental messaging alone. This means that that the messaging-only sites were effectively the control group to which all other measures were compared. The results for the other dummy variables therefore show how the other measures increase the use of reusable cups over-and-above environmental messaging alone. The analyses were conducted for (1) the daily proportion of hot drink sales with reusable cups and (2) the daily total number of hot drink sales.

\section{Results}

\subsection{The Impacts on the Proportion of Hot Drink Sales with Reusable Cups}

Table 1 shows the percentage of hot drink sales with reusable cups at the twelve university and business sites in the before and after periods. The study found that, on average, hot drink sales with reusable cups increased from 3.3 to $7.6 \%$. Three sites saw the biggest increase in sales with reusable cups. Site 1 (which introduced a charge, started selling reusable cups and distributed 200 free reusable cups among their customers) saw an increase from 5.1 to $17.4 \%$. Site 2 (which introduced a discount, started selling reusable cups and distributed 200 reusable cups for free among their customers) saw an increase from 1.8 to $12.4 \%$. Site 8 (which only started selling reusable cups in addition to the environmental messaging) saw an increase from 7.5 to $24.0 \%$. The other sites generally saw smaller increases in hot drink sales with reusable cups.

Table 2 presents the results of the multilevel ITS analysis with the proportion of hot drink sales with reusable cups as the dependent variable. The results suggest that environmental messaging on its own lead to an increase of $2.3 \%$ on average $(B=0.023, \mathrm{SE}=0.009, p<0.05)$. The provision of alternatives further raised the use of reusable cups. Having them for sale within the café increased their use by $2.5 \%(\mathrm{~B}=0.025, \mathrm{SE}=0.007, p<0.001)$ and distributing them for free among customers by another $4.3 \%(B=0.043, \mathrm{SE}=0.008, p<0.001)$.

Table 2. Impacts of the measures on the proportion of hot drink sales with reusable cups.

\begin{tabular}{cc}
\hline Site Characteristic & B (SE) \\
\hline After (versus before) & $0.023(0.009)^{*}$ \\
Reusable cups for sale & $0.025(0.007)^{* * *}$ \\
Free reusable cups provided & $0.043(0.008)^{* * *}$ \\
Discount & $0.005(0.008)^{\text {n.s. }}$ \\
Charge & $0.034(0.014)^{*}$ \\
Time since start of study (in weeks) & $0.002(0.002)^{\text {n.s. }}$ \\
Time since intervention (in weeks) & $-0.006(0.002)^{* *}$ \\
University (versus business) & $-0.039(0.040)^{\text {n.s. }}$ \\
Constant & $0.062(0.034)^{\text {n.s. }}$ \\
\hline
\end{tabular}

Note: ${ }^{*} p<0.05,{ }^{* *} p<0.01,{ }^{* * *} p<0.001$, n.s. $=$ non-significant. 
Table 2 also shows that, while a discount on reusable cups did not make any difference for hot drink sales with reusable cups $(B=0.005, \mathrm{SE}=0.008$, n.s.), a charge on disposable cups increased the use of reusable coffee cups by an extra $3.4 \%(B=0.034, \mathrm{SE}=0.014, p<0.05)$. The effectiveness of the interventions wore off slightly as the study progressed $(B=-0.006, \mathrm{SE}=0.002), p<0.01)$. There were no differences between the university and business sites $(B=-0.039, \mathrm{SE}=0.040, \mathrm{n} . \mathrm{s}$.), and there was no underlying trend in hot drink sales with reusable cups separate from the intervention $(B=0.002$, $\mathrm{SE}=0.002$, n.s.).

\subsection{The Impacts on Total Number of Hot Drink Sales}

In order to examine whether the measures affected overall sales, analyses were conducted with the total number of hot drink sales as the dependent variable (see Table 3). It becomes clear from Table 3 that the measures did not substantially affect hot drink sales. There were no discernible underlying trends, and on average, there were no differences in sales between the university and business sites. The 'constant' was the only significant parameter $(\mathrm{B}=896.303, \mathrm{SE}=388.377, p<0.05)$, showing that the sites sold around 896 hot drinks on average per day. The high standard error for this parameter shows that there was great variation in the total number of sales across the different sites and days.

Table 3. Impacts of the measures on the total number of hot drink sales.

\begin{tabular}{cc}
\hline Site Characteristic & B (SE) \\
\hline After (versus before) & $-5.770(17.026)^{\text {n.s. }}$ \\
Reusable cups for sale & $13.390(14.173)^{\text {n.s. }}$ \\
Free reusable cups provided & $19.922(15.285)^{\text {n.s. }}$ \\
Discount & $-16.723(14.089)^{\text {n.s. }}$ \\
Charge & $-14.491(26.543)^{\text {n.s. }}$ \\
Time since start of study (in weeks) & $-1.302(3.035)^{\text {n.s. }}$ \\
Time since intervention (in weeks) & $-1.129(4.231)^{\text {n.s. }}$ \\
University (versus business) & $-445.652(546.877)^{\text {n.s. }}$ \\
Constant & $896.303(388.377)^{*}$ \\
\hline Note: ${ }^{*} p<0.05$, n.s. $=$ non-significant.
\end{tabular}

\subsection{Long-Term Results at the University of Winchester}

The long-term effects of a coffee cup charge in conjunction with other measures was explored through a case study of a single university site that continued with the intervention and recorded sales for an extended period. Table 4 shows the proportion of hot drink sales with reusable cups at the University of Winchester in the three periods from November 2016-September 2017. The university had introduced a charge on disposable coffee cups as part of the experiment. The charge was subsequently rolled out across the university, and more reusable cups were distributed among students in February 2017. The table shows that, in the period directly following the field study (Period 1), the proportion of hot drink sales with reusable cups increased to $21.9 \%$ in the café in which the charge was trialled (Café 1 in Table 4; Site 1 in Table 1). Table 4 further shows that the charge was also effective at the other two cafés. In the period from November 2016-February 2017, the proportion of hot drink sales with reusable cups at Cafés 2 and 3 stood at $26.6 \%$ and $17.8 \%$, respectively. This means that, overall, $21.1 \%$ of all hot drink sales in that period were with reusable cups.

Table 4. Proportion of hot drink sales with reusable cups at the University of Winchester.

\begin{tabular}{ccccc}
\hline & Café 1 & Café 2 & Café 3 & Total \\
\hline Period 1 (November 2016-February 2017) & $21.9 \%$ & $26.6 \%$ & $17.8 \%$ & $21.1 \%$ \\
Period 2 (February 2017-May 2017) & $37.0 \%$ & $43.0 \%$ & $27.7 \%$ & $33.7 \%$ \\
Period 3 (May 2017-September 20 & $30.4 \%$ & $42.5 \%$ & $29.2 \%$ & $31.6 \%$ \\
\hline Overall & $28.5 \%$ & $34.4 \%$ & $23.5 \%$ & $27.4 \%$ \\
\hline
\end{tabular}

(1) Study Site 1 (see Table 1). 
At the end of February 2017, the university gave away another 2500 reusable coffee cups to students. Table 4 shows that this further boosted the use of reusable cups to $33.7 \%$ on average in the second period, which lasted until the end of the academic year. Café 2 even saw a rate of $43.0 \%$ in this period. The proportion of sales dropped slightly after students had left the university for the 2016-2017 academic session, but remained at a robust 31.6\%. Again, Café 2 saw the strongest hot drink sales with reusable cups at $42.5 \%$.

\section{Discussion}

This paper explored how the use of reusable coffee cups can be encouraged through easily implementable measures. It reported on a field study that was conducted at twelve university and business sites and involved the implementation of different combinations of measures over a five-week period. The study found that both environmental messaging and the provision of alternatives increased the use of reusable cups. While a charge on disposable coffee cups also helped to promote the use of reusable cups, a discount for not using disposable cups did not appear to be effective. These results are in line with prospect theory, which suggests that people are more sensitive to losses than to gains when making decisions [30]. Customers may therefore be more likely to avoid paying a charge on a disposable cup (a loss) than to try to obtain a discount (a gain) by bringing a reusable cup, even if the pricing structure for the two are the same. Another reason that a charge may be more effective than a discount is that the former communicates that bringing a reusable cup is the norm. That is, having to pay extra for a disposable cup suggests that using your own cup is the default expectation [31,32]. Various coffee shops in the U.K. currently provide a discount for bringing your own cup, but public awareness of these discounts and their effectiveness are low. Current estimates are that less than $1 \%$ of customers make use of such discounts [2]. In contrast, a charge may make people more aware of the higher costs of using disposable cups, and act as a habit disruptor against the profligate use of single-use packaging in a similar way as a single-use carrier bag charge does [24-26].

While the effects for the different individual measures were modest, they are additive. That means that greater levels of behaviour change can be established by combining the different measures. The study suggests that the provision of free reusable alternatives in combination with a financial incentive is particularly effective. The two sites that showed the greatest behaviour change combined a charge or a discount with the sale and distribution of reusable cups. People are only likely to change their behaviour if there is a feasible alternative and/or a supportive infrastructure [12]. The catering department of the University of Winchester continued with the charge and recording of sales at their three café sites after the field study had formally finished and distributed a large number of reusable cups for free among their students. This led to a further increase in the use of reusable cups over the rest of the academic session. This shows that, with the right measures and institutional commitment, behaviour change can be even more effective in the long term than in the short term. Hot drink sales with reusable cups remained robust after students had left for the 2016-2017 academic session, suggesting that the measures were equally effective among students and staff.

The study further examined whether the measures affected hot drink sales at the different sites. Many coffee shops may not be willing to take certain measures because they are concerned about potential negative impacts on their business. Indeed, it was initially challenging to find a site that was willing to introduce a charge for this particular reason. Our study suggests that these concerns were unfounded. None of the measures, including the charge on disposable coffee cups, had a negative impact on the total number of hot drink sales. This shows that field experiments, such as the one reported here, may help to allay fears of stakeholders when evaluating different options for behaviour change. It also shows that it is important to work with stakeholders when setting up a field experiment to examine what measures work; measures can only be tested when there are organisations willing to implement them. While the general structure of the experiment was designed by the authors of the paper, the specific measures were implemented in negotiation with the cafes and catering companies that took part in the research [33]. 
Based on this field study, it can be concluded that, by introducing a number of measures, the use of single-use disposable coffee cups can be reduced substantially. The reduction could even be greater with a mandatory charge or a 'latte levy' on disposable coffee cups at the national level [2], as it then becomes more worthwhile for consumers to adapt to the widespread introduction of a charge. Having said that, the measures were tested at a number of workplace cafés at U.K. higher education institutions and office sites. It may be easier to use reusable cups at these places than at, for example, high-street coffee shops. There may be facilities at work where you can clean and store cups. While hot drinks consumed in high-street coffee shops can be sold in crockery, it may be more difficult to adapt to a charge when a hot drink is consumed on the go, as this would require the consumer to bring their own cup. The effectiveness of such a measure would therefore be dependent on the availability of easily portable reusable cups. It would be useful to understand the barriers to using reusable cups for on-the-go hot drink consumption, but also to trial other measures or schemes that may help to reduce the number of single-use disposable coffee cups being used, and them ending up in landfill or as litter.

It has to be noted that our study was relatively small in scale and that the measures were introduced at a limited number of sites, meaning that the results are indicative only. This study took an interrupted time series approach and used the environmental messaging-only sites as the controls. That means that the effectiveness of the other measures are compared to this 'minimal' intervention. There is a remote possibility that the effects of the messaging are caused by external events, such as media reports around the time of the intervention [28]. More research is needed to examine the impacts of a wider introduction of a coffee cup charge or other measures. Zero Waste Scotland, an organisation that aims to support the delivery of a circular economy in Scotland, is currently trialling the effectiveness of disposable coffee cup charges at a larger number of organisations and sites, using a similar methodology to the one used in the current study [34]. Replicating the study at a larger scale will help to determine the reliability of the results. A wider application of a charge on disposable coffee cups may also make it more acceptable, as consumers adapt and get used it. Previous research on carrier bag charges implemented in Wales and England has shown that environmental measures tend to become more popular after their implementation $[24,26]$.

\section{Conclusions}

This study has shown that it is possible to encourage the use of reusable coffee cups through a number of easily implementable measures. This can help reduce the number of single-use disposable coffee cups ending up as litter or as waste in landfill. This in itself will not be sufficient to address all problems posed by single-use packaging and plastics [35]. Disposable coffee cups represent only a small proportion of the total amount of waste generated by households, and all different types of packaging are being littered [8]. Disposable coffee cups have however become a symbol of our throwaway culture in which consumers have become accustomed to the convenience of disposable packaging. Taking action on disposable coffee cups may create awareness of the wider problems associated with plastic pollution. Research on the English plastic bag charge not only showed that it changed behaviour and attitudes relating to plastic bags, but also that the charge acted as a catalyst to raise awareness of plastic waste and pollution in general [26]. The attention given to the publication of the Environmental Audit Committee reports on coffee cups and plastic bottles suggests that there now is momentum to take wider action [2,36]. Further research from the social and behavioural sciences is necessary to provide the evidence needed for effective change.

Acknowledgments: The research reported here was supported by Bewley's Tea and Coffee UK Ltd. The study was conducted with the help of Cardiff University, the University of South Wales, University of Winchester, Imperial College and Contract Caterer Bartlett Mitchell. We would also like to thank David Morton of the University of Winchester for his help with the study. No funds were received for covering the costs to publish in open access.

Author Contributions: W.P. and L.W. conceived and designed the field study. L.W. recruited the sites and organized the data collection. W.P. analysed the data. W.P. led the writing of the paper. All authors contributed to subsequent drafts and read and approved the final draft. 
Conflicts of Interest: The research reported here was sponsored by Bewley's Tea and Coffee UK Ltd. The lead author did not receive any financial payment or any other benefits from the sponsor. The views and opinions expressed in the presentation are those of the authors based on their own professional judgments. The sponsor had no role in the analyses and interpretation of data, in the writing of the manuscript, nor in the decision to publish the results.

\section{References}

1. Eunomia. Written Evidence Submitted by Eunomia Research and Consulting Ltd.; Eunomia Research and Consulting Ltd.: London, UK, 2017.

2. House of Commons Environmental Audit Committee. Disposable Packaging: Coffee Cups; HC 657; House of Commons: London, UK, 2018.

3. Allegra Strategies. Project Cafe UK 2016; Allegra Strategies: London, UK, 2015.

4. Lenaghan, M. Disposable Coffee Cups: Why Are They a Problem, and What Can Be Done? Zero Waste Scotland: Edinburgh, UK, 2017.

5. Pratt, K.; Lenaghan, M. The Carbon Footprint of Scotland's Waste; Zero Waste Scotland: Stirling, UK, 2017.

6. Ziada, H. Disposable Coffee Cup Waste Reduction Study; McMaster University: Hamilton, ON, Canada, 2009.

7. Confederation of European Paper Industries (CEPI). European List of Standard Grades of Paper and Board for Recycling, EN643, 2013 Revision; Confederation of European Paper Industries: Brussels, Belgium, 2013.

8. Keep Britain Tidy. How Clean is England? The Local Environmental Quality Survey of England 2014/15; DEFRA: London, UK, 2015.

9. Blidberg, E.; Leander, E. Plug the Marine Litter Trap. A Pilot Study on Potential Marine Litter Sources in Urban Areas; Nordic Council of Ministers: Copenhagen, Denmark, 2017.

10. Hansen, W.; Christopher, M.; Verbuecheln, M. EU Waste Policy and Challenges for Regional and Local Authorities; Ecologic, Institute for International and European Environmental Policy: Berlin, Germany, 2002.

11. Vlek, C. Essential Psychology for Environmental Policy Making. Int. J. Psychol. 2000, 35, 153-167. [CrossRef]

12. Steg, L.; Vlek, C. Encouraging pro-environmental behaviour: An integrative review and research agenda. J. Environ. Psychol. 2009, 29, 309-317. [CrossRef]

13. Gardner, G.T.; Stern, P.C. Environmental Problems and Human Behavior; Allyn \& Bacon: Needham Heights, MA, USA, 1996; ISBN 0-205-15605-3. (Paperback).

14. Schultz, P.W.; Kaiser, F.G. Promoting pro-environmental behavior. In The Oxford Handbook of Environmental and Conservation Psychology; Clayton, S.D., Ed.; Oxford University Press: Oxford, UK, 2012; pp. 556-580.

15. Abrahamse, W.; Steg, L.; Vlek, C.; Rothengatter, T. The effect of tailored information, goal setting, and tailored feedback on household energy use, energy-related behaviors, and behavioral antecedents. J. Environ. Psychol. 2007, 27, 265-276. [CrossRef]

16. Cialdini, R.B.; Demaine, L.J.; Sagarin, B.J.; Barrett, D.W.; Rhoads, K.; Winter, P.L. Managing social norms for persuasive impact. Soc. Influ. 2006, 1, 3-15. [CrossRef]

17. Cialdini, R.B. Crafting Normative Messages to Protect the Environment. Curr. Dir. Psychol. Sci. 2003, 12, 105-109. [CrossRef]

18. Schultz, P.W. Knowledge, education, and household recycling: Examining the knowledge-deficit model of behavior change. In New Tools for Environmental Protection; Dietz, T., Stern, P.C., Eds.; National Academy of Sciences: Washington, DC, USA, 2002; pp. 67-82.

19. De Groot, J.I.M.; Abrahamse, W.; Jones, K. Persuasive Normative Messages: The Influence of Injunctive and Personal Norms on Using Free Plastic Bags. Sustainability 2013, 5, 1829-1844. [CrossRef]

20. Abrahamse, W.; Steg, L. Social influence approaches to encourage resource conservation: A meta-analysis. Glob. Environ. Chang. 2013, 23, 1773-1785. [CrossRef]

21. Bandura, A. Social Learning Theory; Prentice-Hall: Englewood Cliffs, NJ, USA, 1977.

22. Cialdini, R.B.; Kallgren, C.A.; Reno, R.R. A focus theory of normative conduct: A theoretical refinement and reevaluation of the role of norms in human behavior. Adv. Exp. Soc. Psychol. 1991, 24, 201-234.

23. Carter, N.; Ockwell, D.G. New Labour, New Environment? An Analysis of the Labour Government's Policy on Climate Change and Biodiversity Loss; Centre for Ecology Law \& Policy (CELP), University of York: York, UK, 2007.

24. Poortinga, W.; Whitmarsh, L.; Suffolk, C. The introduction of a single-use carrier bag charge in Wales: Attitude change and behavioural spillover effects. J. Environ. Psychol. 2013, 36, 240-247. [CrossRef] 
25. Thomas, G.O.O.; Poortinga, W.; Sautkina, E. The Welsh Single-Use Carrier Bag Charge and behavioural spillover. J. Environ. Psychol. 2016, 47, 126-135. [CrossRef]

26. Poortinga, W.; Sautkina, E.; Thomas, G.O.; Wolstenholme, E. The English Plastic Bag Charge: Changes in Attitudes and Behaviour; Welsh School of Architecture \& School of Psychology, Cardiff University: Cardiff, UK, 2016.

27. Howell, D. Plastic Bag Charge: Could Fee be Applied to Other Packaging? BBC: London, UK, 2016.

28. Lopez Bernal, J.; Cummins, S.; Gasparrini, A. Interrupted time series regression for the evaluation of public health interventions: A tutorial. Int. J. Epidemiol. 2016, dyw098. [CrossRef] [PubMed]

29. Rasbash, J.; Charlton, C.; Browne, W.J.; Healy, M.; Cameron, B. MLwiN; Version 2.36; Centre for Multilevel Modelling, University of Bristol: Bristol, UK, 2016.

30. Kahneman, D.; Tversky, A. Prospect Theory: An Analysis of Decision under Risk. In Handbook of the Fundamentals of Financial Decision Making; World Scientific Handbook in Financial Economics Series; World Scientific: Singapore, 2012; Volume 4, pp. 99-127, ISBN 978-981-4417-34-1.

31. Cialdini, R.B.; Noah, J. Goldstein Social Influence: Compliance and Conformity. Annu. Rev. Psychol. 2004, 55, 591-621. [CrossRef] [PubMed]

32. Nolan, J.M.; Schultz, P.W.; Cialdini, R.B.; Goldstein, N.J.; Griskevicius, V. Normative Social Influence is Underdetected. Personal. Soc. Psychol. Bull. 2008, 34, 913-923. [CrossRef] [PubMed]

33. Boyle, D.; Harris, M. The Challenge of Co-Production. How Equal Partnerships between Professionals and the Public Are Crucial to Improving Public Services; New Economics Foundation: London, UK, 2009.

34. Lenaghan, M. Cutting Down on Disposable Coffee Cups. A Collaborative Behaviour Change Study on the Impact of Disposable Coffee Cup Charges; Zero Waste Scotland: Stirling, UK, 2018.

35. Pahl, S.; Wyles, K.J.; Thompson, R.C. Channelling passion for the ocean towards plastic pollution. Nat. Hum. Behav. 2017, 1, 697-699. [CrossRef]

36. House of Commons Environmental Audit Committee. Plastic Bottles: Turning Back the Plastic Tide; House of Commons: London, UK, 2017. 